\title{
Optimum Stand Density for Maximum Essential Oil Yield in Commercial Fennel Crops
}

\author{
Linda M. Falzari, ${ }^{1}$ Robert C. Menary, and Valerie A. Dragar \\ School of Agricultural Science, University of Tasmania, Private Bag 54, Hobart \\ Tasmania 7001 Australia
}

Additional index words. Foeniculum vulgare, Apiaceae, Umbelliferae, protandry, essential oil, modelling plant density

\begin{abstract}
Fennel (Foeniculum vulgare Mill.) is grown commercially in Tasmania for the production of a steam-distilled essential oil, which is high in trans-anethole. Often, only the generative canopy is harvested since this contains the bulk of the oil and further this oil is higher in anethole than oil from other parts of the plant. Regardless of whether the whole crop is forage harvested or the generative canopy alone is removed using a combine-harvester, the most efficient oil production occurs when the greatest proportion of the canopy is generative, giving maximum oil yield from a minimum of fresh weight to be processed. A trial was conducted to examine the relationship between stand density and the various yield components of fennel in order to predict the likely effect on yield of increasing stem density as the short term perennial crop matures. As for most crops, planting density and biomass yield are closely related and the optimum planting density was predicted using a mathematical model. The results suggest that an initial stand density of 10 to $12 \mathrm{plants} / \mathrm{m}^{2}$, in a square layout, would produce the greatest yield of essential oil per unit area by maximising the production of the generative canopy. This density also maximises the yield of oil relative to the weight of material to be distilled.
\end{abstract}

Fennel, (Foeniculum vulgare Mill.), is grown commercially in Tasmania for production of steam distilled essential oil, which is high in trans-anethole. Although oil is produced throughout the plant, about $90 \%$ of the anethole is located in the fruits (Hunault et al., 1989). The fennel canopy can be divided into two components: the vegetative canopy, consisting of the leaf and stem material and the generative canopy or flowers. Fennel, as a member of the Apiaceae, produces flowers in compound umbels, with each umbel having several whorls of umbellules. Each plant produces one terminal, primary umbel, on a central leading stem. Several secondary umbels are produced terminally on lateral branches; tertiary umbels are produced on branches arising from the secondary branches and so on. Plants may produce quaternary and even fifth order umbels (Peterson, 1990). The generative canopy forms the upper layer of the crop and is effectively that which is harvested by a combine harvester.

In Tasmania, often only the generative canopy is harvested, thereby reducing the cost of transport to the distillation unit. Somewhat higher oil yields per unit area are achieved

Received for publication 2 Nov. 2005. Accepted for publication 4 Feb. 2006. We gratefully acknowledge the Horticultural Research and Development Corporation, Essential Oils of Tasmania Pty Ltd and Natural Plant Extracts Cooperative who provided funding for this research. We thank Peter Cooper, Neville Mendham, and staff of the University Farm for access to and assistance with the field trial. We thank David Ratkowski for assistance with the statistical analyses.

${ }^{1}$ To whom reprint requests should be addressed; e-mail Linda.Falzari@utas.edu.au. far greater number of secondary umbels in the crop resulted in these producing the bulk of the oil (Peterson, 1990). The percentage of trans-anethole in the oil was not significantly different between the umbel orders, with all showing a steady accumulation of anethole to maturity.

Vrzalova et al. (1988) studied the effect of crop geometry on yield in fennel but do not provide information on crop density.

Several authors have studied the effects of planting density on carrots (Daucus carota L.). Since fennel and carrots are both members of the Umbelliferæ and have similar growth habits, these trials provide useful comparisons.

Noland et al. (1988) found the total seed yield of carrots to follow a parabolic relationship with plant density, with the optimum plant density range for maximum seed yield being 8 to 32 plants $/ \mathrm{m}^{2}$. At high plant densities (36 plants $/ \mathrm{m}^{2}$ in the trial cited), some plants failed to flower (Noland et al., 1988), probably due to self-thinning (Harper, 1977). Gray et al. (1983) found the yield density relationship of carrots to be site specific, with yield increasing with plant density range from 10 to 80 plants $/ \mathrm{m}^{2}$ in two experiments, but density having no effect in another. This indicates that limiting environmental factors may override the effects of plant density in some situations.

Altering carrot plant density altered the contribution of both individual plants and umbel orders to overall yield (Noland et al., 1988). Increasing planting density reduced the number of lateral branches (Gray and Steckel, 1983) and therefore, the number of secondary and tertiary umbels (Noland et al., 1988). At higher densities ( $>30$ to 36 plants $/ \mathrm{m}^{2}$ ) the primary umbel contributed the most to yield (Gray et al., 1983; Noland et al., 1988), while at low densities the tertiary umbels contributed most (Noland et al., 1988). The actual plant densities bringing about these changes varied with the three experimental sites investigated by these authors. The response of the secondary umbels varied with site from either little proportional change with density, to decreasing contribution with higher plant density (Gray and Steckel, 1983). Increasing density decreased seed yield per plant, mostly because each plant produced fewer umbels (Gray et al., 1983).

The effect of density upon biomass yield is perhaps best investigated using correlation analysis. The work of Desmarest (1978) referred to earlier, used the Fischer test to compare means but such a method does not elucidate trends in the data. Early researchers developed mathematical models to predict the nature of the biomass yield/density relationship. Gillis and Ratkowsky (1978) used a simulation study to test two commonly used models of the yield density relationship that were recommended by the review of Willey and Heath, (Willey and Heath, 1969). These were the Bleasdale and Nelder yield-density model (Bleasdale and Nelder, 1960), as modified by Bleasdale (1966) and the Holliday model (Holliday, 1960). Gillis and Ratkowsky (1978) found the Holliday model to be the more robust and to give the best predictions of measured values. The model is as follows: $\omega^{-1}=\alpha+\beta \rho+\gamma \rho^{2}$, 
where $\omega=$ average plant weight, $\rho=$ plant density, and $\alpha, \beta$ and $\gamma$ are constants.

The relationship may be either asymptotic or parabolic (Willey and Heath, 1969) and may change from one form to the other if the growing conditions of the crop are altered (Frappell, 1973). In the Holliday model, $\gamma$ determines the form of the relationship. When $\gamma>0$, the relationship is parabolic. When this term is not significantly $>0$, the relationship is asymptotic (Gillis and Ratkowsky, 1978).

The parabolic relationship is explained by the performance of each plant decreasing with increasing stand density, leading to a general decrease in yield. The asymptotic relationship is explained by self-thinning, whereby some individuals are able to perform at the expense of others. Increasing the numbers of individuals, above a critical point, does not alter yield.

Holliday (1960) suggests that vegetative yield conforms to the asymptotic relationship and reproductive yield to the parabolic curve but this is not true in all cases. For instance, in poppies the relationship is asymptotic for both the yield of total dry matter (vegetative) and for total head or capsule yield (reproductive) (Chung, 1990), except where they lodge at high planting density.

A modification of the Holliday model was used to assess the density effects on the yield components of a first year fennel crop and to estimate the planting density producing the optimum oil yield in year one. A high yield in the first year allows growers to recover their establishment costs early in the life of the crop, adding to economic viability. Since only the generative canopy is harvested, the best yield will be obtained where the maximum resources of the plant are being channelled into the generative canopy.

The current study is designed in part, to further the work ofDesmarest (1978) and to test the effect of stand density on seed and oil yield in fennel under Tasmanian production conditions. Environmental and management practices will vary somewhat between the production area of France, studied by Desmarest (1978) and the local Tasmanian system but perhaps the most important difference with respect to harvesting and oil yield between the two systems is that under Tasmanian production systems the crop is grown for heading, not for forage harvesting. The nature of the relationship may also help to predict the likely effect on yield of annually increasing stem density as the short-term perennial crop matures. This trial also attempts to further the work of Peterson (1990) and examine the effect of density on the architecture of the fennel canopy at other plant densities. This will have a bearing on optimum harvest time and potentially, on oil quality.

The aim of the trial is to optimize production through maximizing the proportion of the generative canopy relative to the vegetative canopy.

\section{Materials and Methods}

The trial was conducted at the University Farm, Cambridge, Tasmania, Australia. This area has a cool, temperate climate. The trial was conducted in a single season, on a $50 \times$ $50 \mathrm{~m}$ area. A commercial mix of two selected fennel populations, C26/C27 (1:2) from Pernod Ricard (France), was sown with a precision drill to give a final plant density of about 100 plants $/ \mathrm{m}^{2}$ with an approximately square planting layout. The trial was sown in late spring and measurements made on the plants in their first season of growth. Full details of plot size, buffer zones, layout, soil preparation, thinning and harvesting are given in a previous publication by Falzari et al. (2005).

The experimental design was of two complete blocks, with replicated treatment plots randomly spaced within each block. Treatments plots were hand-thinned to densities of 4, 12, 25,50 , and 100 plants $/ \mathrm{m}^{2}$. Since there is a tendency in field crops for a square planting layout to be the highest yielding plant spacing geometry(Chung, 1990; Frappell, 1973; Jaaffar and Gardner, 1988; Wells, 1991), plants were thinned to a square spacing.

Unequal replication was used within each block to overcome the greater variability expected at the lower stand densities. To this end, each block contained 5 replications of 4 plants $/ \mathrm{m}^{2}, 3$ replications of 12 plants $/ \mathrm{m}^{2}$ and 2 replications of each of the remaining treatments, 25, 50, and 100 plants $/ \mathrm{m}^{2}$. Each treatment plot consisted of a central datum plot from which measurements were made. Each central datum plot was surrounded by $1 \mathrm{~m}$ of plants also thinned to the treatment density. The remainder of the $50 \times 50 \mathrm{~m}$ crop was left at the original sowing density of 100 plants $/ \mathrm{m}^{2}$.

For each datum plot, the entire plot was harvested at ground level and weighed. A subsample from the adjacent buffer row plants was harvested and its moisture content determined. This subsample was used to calculate the total dry matter per plot.

The umbels were removed from each plant and sorted into primary, secondary and tertiary umbels. There were too few fourth and fifth order umbels to warrant separation, so these were pooled with the tertiary umbels. The total number and total weight of each umbel order was determined.

For each datum plot, each umbel order was steam distilled for $2 \mathrm{~h}$ and the oil collected. The weight of the oil from each sample was measured and the overall oil yield per plot (1 $\mathrm{m}^{2}$ ) calculated. The trans- anethole content of the oil was determined by gas chromatography, using the methods previously detailed (Falzari et al., 2005).

Data collected were: whole plant fresh weight, as total fresh weight per datum plot (TFW); whole plant dry weight, as total dry weight per datum plot (TDW); whole plant moisture content, expressed as percentage dry matter (DM); total umbel weight, expressed as weight of generative canopy (GEN); total fresh weight less total umbel weight to give the weight of the vegetative canopy (VEG); total oil yield (by weight) per plot (OIL) and total anethole yield (by weight) per plot (AN). Each datum plot occupies approximately 1 $\mathrm{m}^{2}$ and these yields are therefore yields per square meter.

The results of this trial were analyzed using SAS (1996) procedures proc glm and proc nlin.

In the first instance, the raw data of yield per unit area were analyzed by ANOVA using proc $\mathrm{glm}$. This procedure was also used to calculate least squares means for yield per area from each data set. These means were used to calculate values of yield per plant $(\omega$ in the Holliday model).

The Holliday model was modified to examine yield per area, instead of yield per plant.

Instead of fitting $\omega^{-1}=\alpha+\beta \rho+\gamma \rho^{2}$, where $\omega=$ yield per plant and $\rho=$ plants $/ \mathrm{m}^{2}$, the variable yield (i.e., yield per $\mathrm{m}^{2}$ ) was fitted, where yield $=$ yield $/$ plant $\times$ plants $/ \mathrm{m}^{2}$; i.e., yield $=$ $\omega \rho$ or $\omega=$ yield $/ \rho$ :

$\omega^{-1}=\alpha+\beta \rho+\gamma \rho^{2}$

$$
\therefore \omega=\frac{1}{\left(\alpha+\beta \rho+\gamma \rho^{2}\right)}
$$

since yield $=\omega \rho$

$$
\therefore \text { yield }=\frac{\rho}{\left(\alpha+\beta \rho+\mu \rho^{2}\right)}
$$

The modified model was then fitted to each data set using proc nlin to obtain estimates of $\alpha, \beta$ and $\gamma$. Bounds statements were used to ensure $\alpha, \beta$ and $\gamma>0$. If $\gamma=0$ the yield had an asymptotic relationship with stand density. If $\gamma>0$, yield had a parabolic relationship with stand density.

Once the parameters were determined, the model was then used to create a data set of predicted values of yield per plant from which a further data set of yield per unit area was plotted to illustrate the full relationship. Optimum planting density for fennel under Tasmanian conditions of production and harvesting were surmised from these predicted relationships.

\section{Results}

Interpretation of the results of the trial aims to demonstrate the relationships between plant density and biomass yield for the vegetative and generative canopies of fennel. The optimum planting density will be that which maximizes the proportion of the generative canopy in the crop, thereby maximising oil yield from a minimum of plant material to be processed.

Table 1 contains the mean data for all the variables that were measured and then used in determination of the predicted values. The mean data for TFW, TDW, and DM for each of the treatment planting densities reflects the whole plant canopy (vegetative plus generative); the mean data for the total weight of umbels (primary, secondary and tertiary) describes the generative canopy; oil yield from each umbel order and total oil yield are also given. Analysis of variance gives an interpretation of differences between means but not the full scope of the relationship between the variables and stand density. So, for each variable ANOVA is used to compare the observed means and then the continuous relationship is examined by plotting the predicted values.

Total biomass Analysis of variance showed that planting density had a statistically significant effect $(p=0.0001)$ on total biomass yield 
Table 1. The effect of density on biomass yield parameters of fennel (standard errors in parentheses)

\begin{tabular}{|c|c|c|c|c|c|c|}
\hline Plant density (plants $/ \mathrm{m}^{2}$ ) & 4 & 12 & 25 & 50 & 100 & Significance \\
\hline Total plant fresh weight $\left(\mathrm{kg} \cdot \mathrm{m}^{-2}\right)$ & $\begin{array}{l}1.420 \mathrm{~d}^{\mathrm{z}} \\
(0.010)\end{array}$ & $\begin{array}{l}2.143 \mathrm{c} \\
(0.147)\end{array}$ & $\begin{array}{l}2.430 \mathrm{c} \\
(0.197)\end{array}$ & $\begin{array}{l}3.385 \mathrm{~b} \\
(0.251)\end{array}$ & $\begin{array}{l}4.030 \mathrm{a} \\
(0.177)\end{array}$ & $* * *$ \\
\hline Total plant dry weight $\left(\mathrm{kg} \cdot \mathrm{m}^{-2}\right)$ & $\begin{array}{l}0.606 \mathrm{c} \\
(0.044)\end{array}$ & $\begin{array}{c}0.853 \mathrm{bc} \\
(0.085)\end{array}$ & $\begin{array}{l}0.965 \mathrm{~b} \\
(0.117)\end{array}$ & $\begin{array}{l}1.238 \mathrm{a} \\
(0.184)\end{array}$ & $\begin{array}{l}1.368 \mathrm{a} \\
(0.119)\end{array}$ & $* * *$ \\
\hline Dry matter content $(\%)$ & 43 a (1) & $40 \mathrm{ab}(2)$ & $40 \mathrm{ab}(3)$ & 36 bc (3) & $34 \mathrm{c}(2)$ & $* * *$ \\
\hline Fresh weight of primary umbels $\left(\mathrm{g} \cdot \mathrm{m}^{-2}\right)$ & $\begin{array}{l}0.021 \mathrm{~d} \\
(0.001)\end{array}$ & $\begin{array}{l}0.048 \mathrm{c} \\
(0.003)\end{array}$ & $\begin{array}{l}0.070 \mathrm{~b} \\
(0.005)\end{array}$ & $\begin{array}{l}0.116 \mathrm{a} \\
(0.013)\end{array}$ & $\begin{array}{l}0.113 \mathrm{a} \\
(0.007)\end{array}$ & $* * *$ \\
\hline Fresh weight of secondary umbels $\left(\mathrm{g} \cdot \mathrm{m}^{-2}\right)$ & $\begin{array}{l}0.161 \mathrm{~b} \\
(0.009)\end{array}$ & $\begin{array}{c}0.229 \mathrm{ab} \\
(0.031)\end{array}$ & $\begin{array}{l}0.248 \mathrm{a} \\
(0.045)\end{array}$ & $\begin{array}{c}0.219 \mathrm{ab} \\
(0.049)\end{array}$ & $\begin{array}{l}0.175 \mathrm{~b} \\
(0.024)\end{array}$ & * \\
\hline Fresh weight of tertiary umbels $\left(\mathrm{g} \cdot \mathrm{m}^{-2}\right)$ & $\begin{array}{l}0.268 \mathrm{a} \\
(0.018)\end{array}$ & $\begin{array}{l}0.214 \mathrm{a} \\
(0.030)\end{array}$ & $\begin{array}{l}0.124 \mathrm{~b} \\
(0.020)\end{array}$ & $\begin{array}{c}0.068 \mathrm{bc} \\
(0.025)\end{array}$ & $\begin{array}{l}0.043 \mathrm{c} \\
(0.014)\end{array}$ & $* * *$ \\
\hline Total fresh weight of umbels $\left(\mathrm{g} \cdot \mathrm{m}^{-2}\right)$ & $\begin{array}{l}0.449 \mathrm{a} \\
(0.022)\end{array}$ & $\begin{array}{l}0.492 \mathrm{a} \\
(0.058)\end{array}$ & $\begin{array}{l}0.441 \mathrm{a} \\
(0.067)\end{array}$ & $\begin{array}{l}0.403 \mathrm{a} \\
(0.085)\end{array}$ & $\begin{array}{l}0.330 \mathrm{a} \\
(0.044)\end{array}$ & NS \\
\hline Oil yield from primary umbels $\left(\mathrm{g} \cdot \mathrm{m}^{-2}\right)$ & $\begin{array}{l}0.84 \mathrm{~d} \\
(0.05)\end{array}$ & $\begin{array}{l}2.02 \mathrm{c} \\
(0.16)\end{array}$ & $\begin{array}{l}2.52 \mathrm{c} \\
(0.20)\end{array}$ & $\begin{array}{l}4.27 \mathrm{a} \\
(0.52)\end{array}$ & $\begin{array}{l}3.50 \mathrm{~b} \\
(0.15)\end{array}$ & $* * *$ \\
\hline Oil yield from secondary umbels $\left(\mathrm{g} \cdot \mathrm{m}^{-2}\right)$ & $\begin{array}{c}5.95 \mathrm{ab} \\
(0.31)\end{array}$ & $\begin{array}{l}7.88 \mathrm{a} \\
(1.00)\end{array}$ & $\begin{array}{l}7.03 \mathrm{a} \\
(0.90)\end{array}$ & $\begin{array}{c}6.85 \mathrm{ab} \\
(1.50)\end{array}$ & $\begin{array}{l}4.73 \mathrm{~b} \\
(0.84)\end{array}$ & NS \\
\hline Oil yield from tertiary umbels $\left(\mathrm{g} \cdot \mathrm{m}^{-2}\right)$ & $\begin{array}{l}6.66 \mathrm{a} \\
(0.46)\end{array}$ & $\begin{array}{l}5.62 \mathrm{a} \\
(0.84)\end{array}$ & $\begin{array}{l}2.98 \mathrm{~b} \\
(0.46)\end{array}$ & $\begin{array}{c}1.82 \mathrm{bc} \\
(0.73)\end{array}$ & $\begin{array}{l}0.81 \mathrm{c} \\
(0.05)\end{array}$ & $* * *$ \\
\hline Total oil yield $\left(\mathrm{g} \cdot \mathrm{m}^{-2}\right)$ & $\begin{array}{l}13.4 \mathrm{a} \\
(0.63)\end{array}$ & $\begin{array}{l}15.5 \mathrm{a} \\
(1.75)\end{array}$ & $\begin{array}{c}12.5 \mathrm{ab} \\
(1.35)\end{array}$ & $\begin{array}{c}12.9 \mathrm{ab} \\
(2.65)\end{array}$ & $\begin{array}{l}9.0 \mathrm{~b} \\
(0.88)\end{array}$ & NS \\
\hline Anethole in oil from primary umbels $(\%)$ & $75.5 \mathrm{a}$ & $72.8 \mathrm{~b}$ & $73.5 \mathrm{ab}$ & $71.3 \mathrm{~b}$ & $72.5 \mathrm{~b}$ & $*$ \\
\hline Anethole in oil from secondary umbels $(\%)$ & $72.0 \mathrm{a}$ & $69.8 \mathrm{bc}$ & $69.8 \mathrm{c}$ & $70.3 \mathrm{bc}$ & $71.5 \mathrm{ab}$ & $* *$ \\
\hline Anethole in oil from tertiary umbels $(\%)$ & $69.5 \mathrm{~b}$ & $69.7 \mathrm{~b}$ & $70.5 \mathrm{~b}$ & $73.0 \mathrm{a}$ & $74.8 \mathrm{a}$ & $* * *$ \\
\hline
\end{tabular}

${ }^{2}$ For each umbel order, means annotated with the same subscript are not significantly different at the 5\% probability level.

$\mathrm{NS}^{*, * * * * * *}$ Density effect on means is nonsignificant or significant at the $5 \%, 1 \%$, or $0.1 \%$ probability level, respectively.

per unit area on both a fresh and dry weight basis, as well as on the moisture content of the harvested material. Total biomass increased with each increase in planting density on both a fresh and dry weight basis. Tests of differences between individual means suggest that the dry matter content was higher at low plant densities and decreased as plant density increased. That is, moisture content is higher at high density.

Biomass production per unit area follows an asymptotic relationship since the calculated value of $\gamma=0$ for both TFW and TDW. The values of $\alpha$ and $\beta$ are 2.87 and 0.23 , respectively for TFW and 4.91 and 0.72 , respectively for TDW. The predicted curves give a good match with actual values for all except the 25 plants $/ \mathrm{m}^{2}$ density.

Examination of the residuals from both statistical methods (proc reg and proc nlin) shows that values produced by 'proc nlin' give a better fit at lower densities than proc reg, for both TFW and TDW.

From the curves in Fig. 1, it can be deduced that under these growing conditions fennel will produce a maximum of $4 \mathrm{~kg} \cdot \mathrm{m}^{-2}\left(40 \mathrm{t} \cdot \mathrm{ha}^{-1}\right)$ fresh matter or $1.4 \mathrm{~kg} \cdot \mathrm{m}^{-2}\left(14 \mathrm{t} \cdot \mathrm{ha}^{-1}\right)$ dry matter.

Generative and vegetative canopies The examination of the generative canopy was based on fresh weight of the umbels. ANOVA and comparison of individual means (Table 1) showed the fresh weight of primary umbels per unit area is significantly increased $(p=0.0001)$ with increasing plant density to 50 plants $/ \mathrm{m}^{2}$. There is no significant difference between 50 and 100 plants $/ \mathrm{m}^{2}$. The fresh weight yield of secondary umbels is also influenced by density since the overall $\mathrm{F}$ test is significant at the $5 \%$ level. The yield of the generative canopy appears to increase with density to a peak at 25 plants $/ \mathrm{m}^{2}$ and then to fall again. The fresh weight yield of tertiary umbels decreases with increasing planting density, although differences between adjacent means are not significant. The total fresh weight of umbels was not significantly affected by plant density over the range of densities measured but was trending downwards at plant densities greater than 12 plants $/ \mathrm{m}^{2}$.

When the data for the total fresh weight of umbels were fitted to the yield-density model of Holliday (1960), the parameters $\alpha$ and $\beta$ were 1.30 and 1.84 , respectively. The parameter $\gamma$ was found to be 0.012 i.e., $>0$, indicating a parabolic function. When plant density is increased above an optimum, the total yield of umbels per plant will decrease. Figure 2 compares the predicted curve and observed values for the yield per area of the generative canopy. The curve peaks at 10 plants $/ \mathrm{m}^{2}$.

The vegetative canopy is the total canopy less the weight of the umbels (per unit area). ANOVA showed density to have a significant effect $(p<0.001)$ on the weight of the vegetative canopy. The weight of the vegetative canopy increased with increasing plant density from

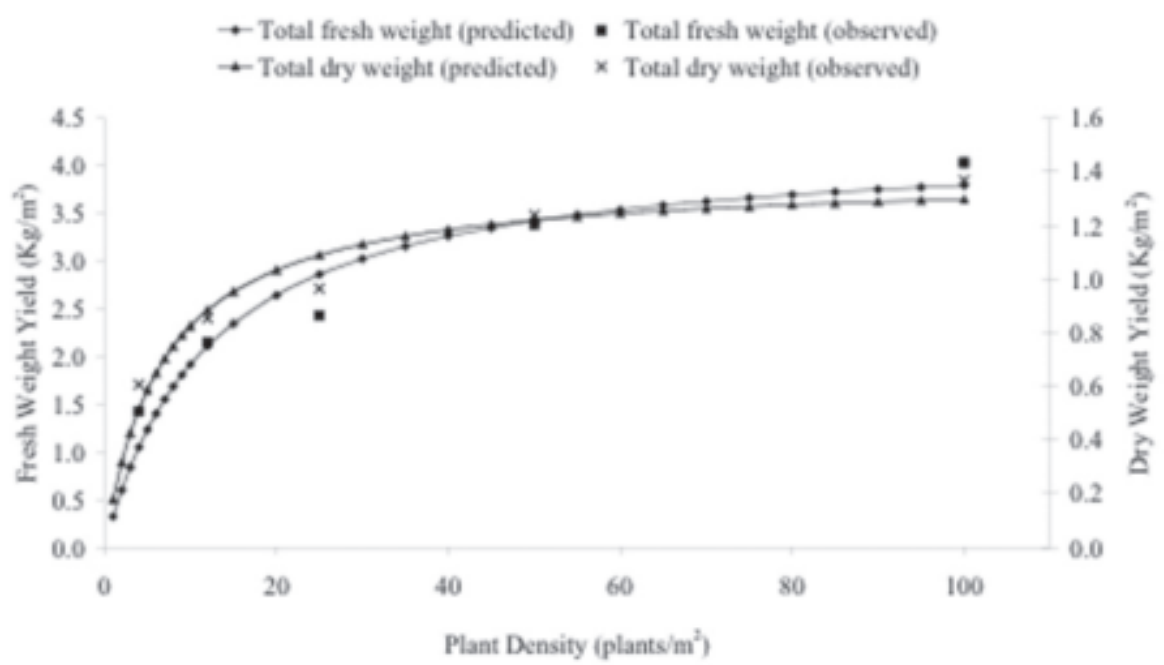

Fig. 1. Predicted and observed whole plant yields for total fresh weight and total dry weight per unit area ( $\mathrm{NB}=$ no curve fitted to observed values).
$0.97 \mathrm{~kg} \cdot \mathrm{m}^{-2}$ at 4 plants $/ \mathrm{m}^{2}$ to $3.70 \mathrm{~kg} \cdot \mathrm{m}^{-2}$ at 100 plants $/ \mathrm{m}^{2}$. All means were significantly different with the exception of the difference between 12 plants $/ \mathrm{m}^{2}$ and 25 plants $/ \mathrm{m}^{2}$.

The Holliday model showed the vegetative yield per unit area to be asymptotic with $\gamma=0$. $\alpha$ and $\beta$ are 5.13 and 0.23 , respectively. The predicted and observed yields per unit area of the vegetative canopy are shown in Figure 2 . The vegetative yield continues to increase under the range of densities covered by this trial but maximum yield appears to be in the order of $3.5 \mathrm{~kg} \cdot \mathrm{m}^{-2}$ or $35 \mathrm{t} \cdot \mathrm{ha}^{-1}$.

Oil yield and anethole yield ANOVA and comparison of means shows that the oil yield from the primary and tertiary umbels is significantly influenced by density (Table 1) but under this statistical analysis the oil yield of secondary umbels is not affected by plant density. The oil yield of the primaries increases with density while that of the tertiary umbels falls. 


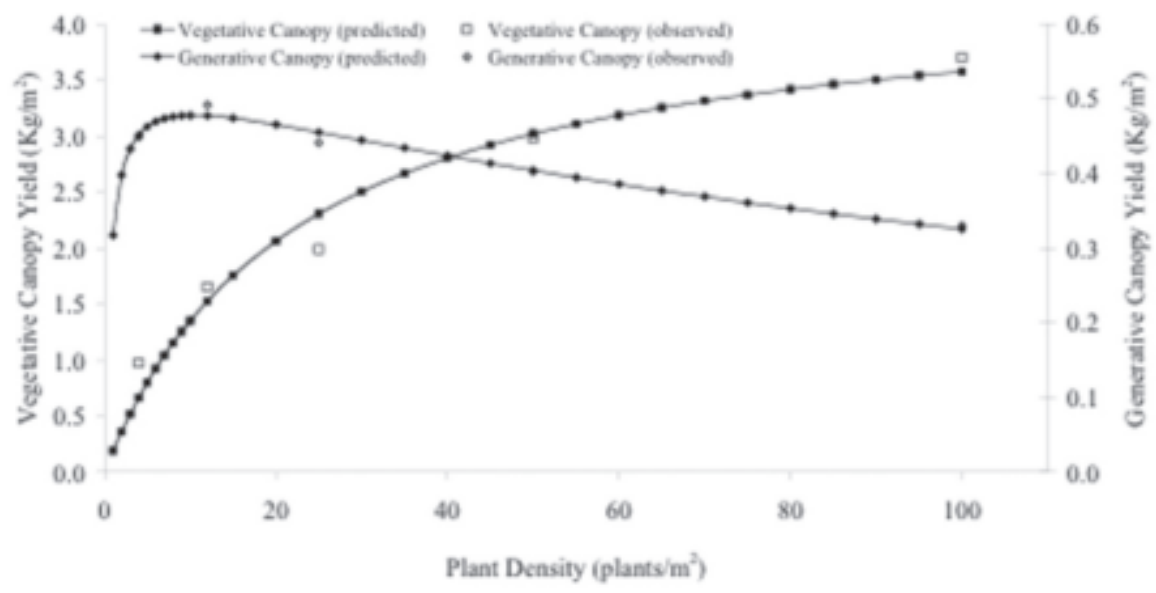

Fig. 2. Predicted and observed yields from the vegetative and generative canopies per unit area $(\mathrm{NB}=$ no curve fitted to observed values).

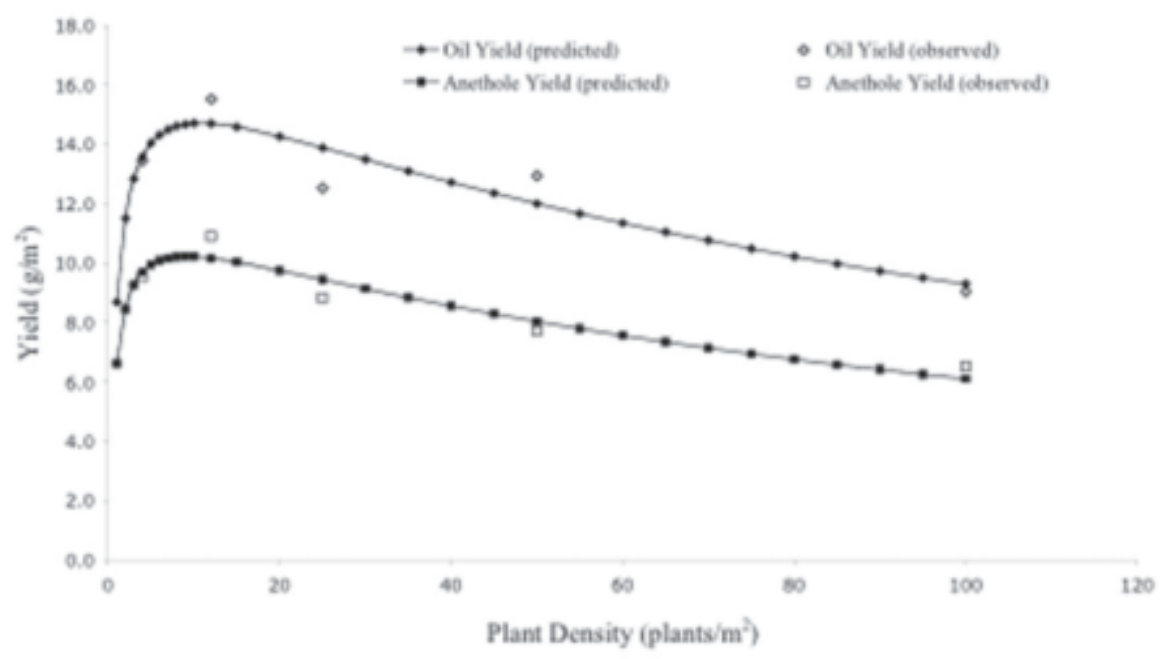

Fig. 3. Predicted and observed yields of fennel oil and anethole per unit area (NB $=$ no curve fitted to observed values).

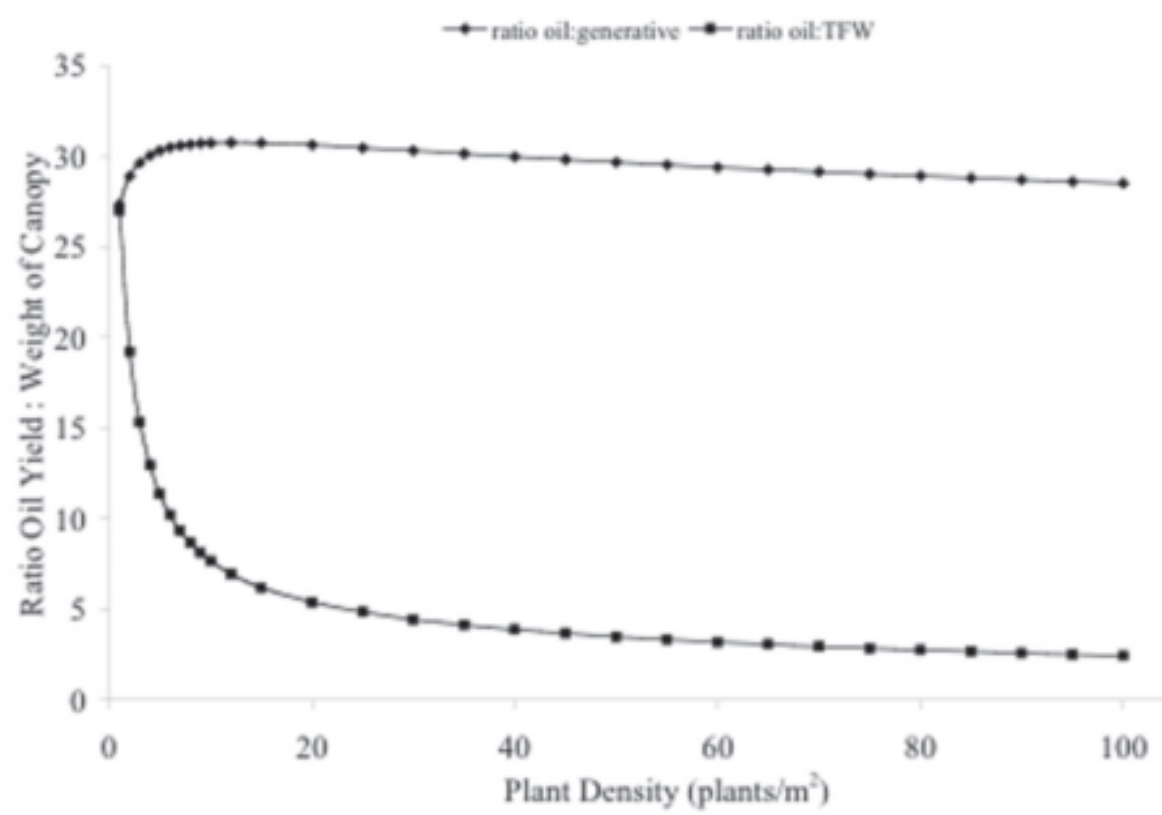

Fig. 4. The relationships between oil yield and total fresh weight and between oil yield and the weight of the generative canopy.
The percentage of anethole in the oil from the primary umbels is significantly higher for 4 plants $/ \mathrm{m}^{2}$ than for any other density. In the second-order umbels, it is significantly higher for 4 plants $/ \mathrm{m}^{2}$ than for 12,25 or 50 plants $/ \mathrm{m}^{2}$, but not for 100 plants $/ \mathrm{m}^{2}$. Among the tertiary umbels, the trend is for increasing density to increase the percentage anethole in the oil.

When fitted to the data for the total yield of oil, the Holliday model gave estimates of the parameters as $\alpha=0.057, \beta=0.057$ and $\gamma$ $=0.0005$. For anethole yield the parameters were estimated to be $\alpha=0.067, \beta=0.083$ and $\gamma=0.0008$. Since for both variables, $\gamma>$ 0 , parabolic relationships are indicated. The resultant predicted oil yield and anethole yield values are shown in Fig. 3. Oil yield peaks at a plant density of 11 plants $/ \mathrm{m}^{2}$, while anethole yield peaks at 9 plants $/ \mathrm{m}^{2}$.

Figure 4 shows the relationship between plant density and the ratio of oil to both TFW and GEN. The efficiency of oil production is based upon these ratios, since these determine the amount of plant material to be processed in order to extract the oil. The ratio of oil to TFW is important when the crop is forage harvested and the ratio of oil to GEN is important when only the umbels are harvested. The figure shows that the efficiency of forage harvesting will fall continuously with increasing plant density, over the range tested, while the efficiency of oil extraction peaks at 12 plants $/ \mathrm{m}^{2}$ when the generative canopy alone is harvested.

\section{Discussion}

This analysis of the trial data allows the continuous relationship between plant density and the yield variables to be examined, providing a better understanding of the trends in the data than can be achieved through ANOVA and comparison of individual means. Since the yield density relationship can be altered by site or local environmental conditions, the actual values for the model variables obtained from one site and in one season will not apply in all situations.

The higher moisture content of plants at higher planting densities is attributed to the lower plant densities having a relatively lower volume of pithy primary-stem material. As density increases, the amount of primary-stem material increases. This interaction between plant density and moisture content means that the total fresh weight curve is not a true reflection of the total dry weight curve, however, Fig. 1 shows them to be similar. The examination of the generative canopy alone was based on fresh weight because dry weight was not measured for individual umbels. This is a shortcoming of the experimental design brought about because the small weight of umbels in each sample precluded subsampling for moisture content, as all were required for distillation.

The overall biomass yield per unit area for fennel is asymptotic. Fennel produces compensatory growth at low densities in order to fill the available space. Each plant is smaller at higher planting densities but the overall biomass on both a fresh and dry weight basis tends towards the respective asymptotic level. 
The data collected here support Holliday's suggestion (Holliday, 1960) that vegetative yield is asymptotic while generative yield is parabolic. In this case, both oil yield and anethole content can be thought of as generative yield, since the oil was only extracted from the umbels and not from the vegetative canopy.

Although the trans-anethole content is relatively constant across the densities, it is perhaps influenced by the relative maturity of the umbels. This varies with density because as the relative number of umbels within each order increases, so does the range of umbel maturity. Trans-anethole content increases with umbel maturity (Peterson, 1990), so a higher proportion of immature umbels will decrease the anethole content of the oil.

The yield-density models and the ANOVA appear to give different predictions about total umbel yield, i.e., the yield of the generative canopy, at high densities. The yield-density models suggest that increasing density above a given optimum leads to a decrease in yield. The ANOVA showed no significant differences in yield for any of the densities tested. It is thought that this is a result of the high variance associated with the data. The ANOVA was not sensitive enough to detect differences between the treatments.

Regression analysis is more appropriate to this type of experiment, where increasing levels of the same treatment are applied. The trend in the means is for yield to fall continuously as density is increased above 12 plants $/ \mathrm{m}^{2}$. Again, Holliday's suggestion that generative yield follows a parabolic function is supported.

Consideration of the ratio of the total umbels to the total fresh weight gives a measure of the allocation of resources within the crop to generative growth. This ratio is ascertained by dividing the mean weight of the generative canopy by TFW. The ratios for $4,12,25,50$, and 100 plants $/ \mathrm{m}^{2}$ are $46 \%, 28 \%, 22 \%, 13 \%$, and $9 \%$ respectively. So, the lower the density, the greater the proportion of umbels in the crop and the greater the allocation of resources into the economically valuable portion of the crop.

A previous publication (Falzari et al., 2005) was based upon comparison of the means and indicated that 50 plants $/ \mathrm{m}^{2}$ was the optimum planting density since the narrower canopy depth would be more efficient to harvest and was not seen to decrease yield. However, upon examination of the continuous relationship using regression analysis it is shown that oil yield and anethole yield per unit area peak at 10 and 9 plants $/ \mathrm{m}^{2}$ respectively and that the most efficient extraction of oil is at 12 plants $/ \mathrm{m}^{2}$ when only the umbels are harvested or as low as $1 \mathrm{plant} / \mathrm{m}^{2}$ for forage harvesting. These low densities also have the advantage of optimising canopy architecture for pollination of this protandrous crop (Falzari et al., 2005).

There are practical problems associated with mechanical harvesting of only the umbels at low planting densities since the umbels are spread throughout the canopy. A combine harvester would generally separate the seed material from the stem material but a proportion of the stem material is useful within the distillation vat to prevent tight packing of the material and poor penetration of the steam. Harvesting in Tasmania is generally carried out with a modified combine harvester.

The yield density relationships for fennel appear to be parabolic functions. Therefore, if density exceeds a critical point, yields will be reduced. The density trial conducted supports the recommended planting density of 10 to 12 plants $/ \mathrm{m}^{2}$. However, this can be achieved by various planting arrangements. Adopting a square planting layout, as used in this trial design, is expected to increase yield.

The average plant weight increases to an asymptotic value as plant density increases. This is reflected in the total yield per unit area. Once a maximum yield per unit area is reached, further increases in plant density do not result in further increases in total dry weight per unit area for the above ground portion of the crop. The number of plants falls due to self-thinning, and the overall yield is asymptotic. That is, the total canopy is self-thinning and has an asymptotic relationship to plant density.

From a commercial point of view, oil yield per unit area and the anethole content of the oil, are the most important variables.

Since self-thinning will have a tendency to bring the crop to a natural stand density of 70 plants $/ \mathrm{m}^{2}$, management practices such as harrowing should be used to maintain the density at the ideal level of 12 plants $/ \mathrm{m}^{2}$ to achieve the best commercial outcome.

\section{Literature Cited}

Bleasdale, J.K.A. 1966. Plant growth and crop yield. Ann. Appl. Biol. 57:173-182.

Bleasdale, J.K.A. and J.A. Nelder. 1960. Plant population and crop yield. Nature 188:342.

Chung, B. 1990. Effects of plant population density and rectangularity on the growth and yield of poppies (Papaver somniferum ). J. Agr. Sci. Cambridge 115:239-245.

Desmarest, P. 1978. New aspects of fennel cultivation in france. Acta Hort. 73:289-295.

Földesi, D. and L. Hornok. 1992. Fennel, p. 162-166. In: L. Hornok (ed.). Cultivation and processing of medicinal plants. Wiley, Chichester.

Falzari, L.M., R.C.Menary, and V.A. Dragar. 2005. Reducing fennel stand density increases pollen production, improving potential for pollination and subsequent oil yield. HortScience 40(3):629-634

Frappell, B.D. 1973. Plant spacing of onions. J. Hort. Sci. 48:19-28.

Gillis, P.R. andD.A. Ratkowsky. 1978. The behaviour of estimators of the parameters of various yielddensity relationships. Biometrics 34:191-198.

Gray, D. and J.R.A. Steckel. 1983. Seed quality in carrots: the effects of seed crop plant density, harvest date and seed grading on seed and seedling variability. J. Hort. Sci. 58:393-401.

Gray, D., J.R.A.Steckel, and J.A. Ward. 1983. Studies on carrot seed production: Effects of plant density on yield and components of yield. J. Hort. Sci. 58:83-90.

Harper, J.L. 1977. Population Biology of Plants. Academic Press, London.

Hart, M.A. 1987. Department of primary industry notes: Fennel. Austral. Govt. Printing Serv., Hobart, Tasmania.

Holliday, R. 1960. Plant population and crop yield. Nature, 186:22-24.

Hunault, G., P. Desmarest and J. du Manoir. 1989. XI Foeniculum vulgare Miller: Cell culture, regeneration, and the production of anethole, $\mathrm{p}$. 185-209. In: Y.P.S. Bajaj (ed.). Medicinal and aromatic plants. Springer-Verlag, Berlin.

Jaaffar, Z. and F.P.Gardner. 1988. Canopy development, yield, and market quality in peanut as affected by genotype and planting pattern. Crop Sci. 28:299-305.

Noland, T.L., J.D. Maguire, R.N. Oliva, K.J. Bradford, J.L. Nelson, D. Grabe, and S. Currans. 1988. Effect of plant density on carrot seed yield and quality under seed-to-seed production systems in California, Oregon, and Washington. J. Appl. Seed Prod. 6:36-43.

Peterson, L.E. 1990. A study of some factors affecting the yield and composition of fennel oil (Foeniculum vulgare Mill.). PhD diss. Univ. Tasmania.

Vrzalova, J., B.Kocourkova, and J. Stavkova. 1988. The response of two cultivars of fennel (Foeniculum vulgare Mill./Thell) to row spacing. Shornik UVTIZ, Zahradnictvi 15:101-106.

Wells, R. 1991. Soybean growth response to plant density: Relationships among canopy photosynthesis, leaf area, and light interception. Crop Sci. 31:755-761.

Willey, R.W. and S.B. Heath. 1969. The quantitative relationship between plant population and crop yield. Adv. Agron. 21:281-321. 